\title{
Regional audit of depot neuroleptic usage in adults with learning disabilities
}

\author{
Shaun Gravestock
}

\begin{abstract}
A provious survey (Grovestock, 1996) assessed factors aseociated with depot neuroleptic usage in 79 adutts with barning dlscbilities using mainhy community-based services. The dota informed consensus standord setting and this ouctt focusing on 32 out of 79 original subjects. At two year follow-up, five subjects had been with drawn from depots; there was a signilicant $(P<0.001)$ reduction in subjects' median depot dosage and reduced concomitont usage of ord neuroleptics and anticholinergics. The importance of completing the cudit cycle and other poychotrople medication monltoring studies in community lecining discabilities services are discussed.
\end{abstract}

Previous UK psychoactive medication surveys mainly studied heterogeneous hospital populations of adults with learning disabilities (LD) rather than community LD service users. Surveys estimate the prevalence of psychotropic drug usage in diverse hospital and community populations as 30-50\% and 10-36\% of adults with $L D$ respectively (Aman, 1987; Clarke et al, 1990). Other studies showed that 8-10\% of mental handicap hospital in-patients (Wressell et al, 1990; Kohen et al, 1993) and 5\% of adults with $L D$ resettled in the community (Thinn et al, 1990) recetve depot neuroleptics.

Despite concerns about fatalities (Craft \& Schiff, 1980), various depot neuroleptics are used as antipsychotics and as adjunctive treatments for the wide range of behavioural disturbances occurring in adults with LD. Broader concerns have been raised about the extent and monitoring of depot usage in generic psychiatric services (Crammer \& Eccleston, 1989).

\section{The study}

The author devised a semi-structured checklist to be completed by consultants or their trainees for each survey subject. The 1992 survey identified 79 adults with $L D$ receiving depot neuroleptics under the in- or out-patient care of ten district consultants in the psychiatry of LD in the South East Thames Region (Gravestock, 1996). Data feedback and discussion at a Regional Psychiatry of Learn- ing Disabilities Specialist Sub-Committee meeting resulted in consultants reaching consensus agreement about the following clinical practice standards:

(a) All patients are to be reviewed by a consultant or trainee psychiatrist at least every six months.

(b) All patients satisfying one or more of the below criteria are to recelve the minimum depot dosage needed to stabilise their mental state and behaviour:

(i) aged over 60 years

(ii) severe $\mathrm{LD}$

(iii) known to have epilepsy

(tv) not known to have a functional psychotic disorder

(v) receiving doses outside British National Formulary (BNF, British Medical Association \& The Pharmaceutical Society. 1993) 1993 limits.

Applying these standards to the 1992 survey we identified 32 out of 79 original subjects (Gravestock, 1996), to be monitored over 24 months to audit changes in clinical practice (see Table 1). Consultants or trainees completed another checklist to update data on each subject for 1994. As in previous studies (Wressell et al, 1990), all depot dosages were converted into daily oral chlorpromazine milligramme equivalents (CPZE) to allow comparison. Checklist data from 1992 and 1994 were compared statistically using the SAS/STAT programme (SAS Institute, 1989).

\section{Findinge}

Of the 32 audit subjects 24 were male and 8 were female; their modal age was 32 years Irange 22 77]: 13 had mild LD, 12 moderate $L D$, and seven severe $L D$. While 18 lived in staffed residences, seven lived with their families or independently and seven were in-patients at mental handicap hospital units. Their depots were fluphenazine decanoate $(n=14)$, zuclopenthixol decanoate $(n=9)$, flupenthixol decanoate $(n=5)$, haloperidol decanoate $(n=3)$, and pipothiazine palmitate 
$(n=1)$. They had recelved depots for a median of five years [range 0.5-16].

Their ICD-9 (World Health Organization, 1978) psychiatric diagnoses were: atypical childhood psychoses (autism) ( $n=10)$; schizophrenic psychoses $(n=8)$; affective paranoid or unspecified psychoses $(n=6)$; and other diagnoses ( $n=2$; one obsesstve-compulstve disorder and one explostve personality disorder). Six subjects had no psychiatric diagnosis but exhibited chronic overactive. aggressive, self-injurious or destructive challenging behaviours.

Table 1 shows the inclusion criteria of the 32 1992 audit subjects and the changes occurring by 1994 when 27 subjects remained on depots. Table 2 shows the changes in subjects' clinical condition and psychiatrists' clinical practice over 1992-94. Medication side-effects included tremor, dribbling saltva, weight gain and tardive dyskinesia.

Concerning their reported attitudes towards depot injections, in 1992, 19 subjects and 20 carers had positive attitudes, 11 subjects and eight carers were uncertain, while two subjects and four carers had negattve attitudes. By 1994, 19 subjects and 23 carers had posittve attitudes, stx subjects and four carers were uncertain, while two subjects had negattve attitudes.

\section{Comment}

These findings may be cautiously compared with those of larger hospital (Wressell et al, 1990) and community (Thinn et al, 1990) medication monitoring surveys and a regional audit in primary care, out- and in-patient populations with normal intellect (Crammer \& Eccleston, 1989). As expected, study subjects with LD had a broader range of psychiatric diagnoses and challenging behaviours than those without $L D$. This audit also suggested the wide range of depots and dosages used and the greater use of zuclopenthixol in LD services (Gravestock, 1996).

As in mental handicap hospitals (Craft \& Schiff, 1980), the audit showed no specific problems with depot usage in adults with $L D$ and epilepsy. However, as all five patients withdrawn from depots had epilepsy and three still exhibited unstable behaviour, future audit focusing on withdrawal from depots would be useful.

In spite of statistically significant medication reductions, the stability of subjects' mental state and behaviour was clinically maintained or improved over two years. These findings also reflect the chronic and fluctuating natural course of psychotic and behavioural disorders in LD patients over time (Fraser \& Nolan, 1994).

Compared with similar surveys (Crammer \& Eccleston, 1989; Kohen et ah, 1993) this audit
Table 1. Audit subjects

\begin{tabular}{lcl}
\hline Incluaton criteria & $\begin{array}{c}1992 \\
(n-32)\end{array}$ & $\begin{array}{l}1994 \\
\left(n-27^{\circ}\right)\end{array}$ \\
\hline Psychiatic diagnoses & 10 & 8 \\
$\quad$ Autism & 2 & 2 \\
Other & 6 & 3 \\
None & 14 & 9 \\
Epilepsy & 8 & 5 \\
Depot dosages outside BNF' limits & 8 & 3 \\
Psychiatric review not every 6 months & 7 & 5 \\
Severe LD & 3 & 3 \\
Aged over 60 years & 3 & \\
\hline
\end{tabular}

- 5 subjects withdrown from depots by 1994

1. BNF, British National Formulary

found higher baseline and follow-up concomitant prescription of oral neuroleptics and anticholinergics and a high occurrence of sideeffects. The data supports ongoing controversies about prescribing neuroleptics for people with $L D$ and non-specific disturbed behaviours (Manchester, 1993). On the other hand, few subjects and their carers had clearly negative attitudes towards depot injections.

The audit data showed the following improvements in clinical practice over two years:

(a) an increase from $24 / 32(75 \%$ ) to $23 / 27$ (85\%) subjects for whom the minimum standard was met for the frequency of psychiatric reviews

(b) an overall statistically significant reduction in depot dosages with better adherence to BNF dose limits

(c) an overall reduction in concomitant oral drug usage

(d) despite (b) and (c), a modest decrease in subjects with unstable mental state and behaviour.

Improvement (a) above indicated better followup practices than in Crammer \& Eccleston's (1989) audit which revealed uncertain follow-up arrangements for two-thirds of general adult psychiatric patients.

Unlike a similar more sophisticated audit (Harvey \& Cooray, 1993) this audit did not include monitoring the use of as required psychoactive medications, but both audits emphasised the necessity of completing the audit cycle and establishing ongoing medication monitoring systems. This way, improvements in clinical practice can be both achieved and maintained by setting higher standards for further audits.

Future psychotropic medication audits could include: concomitant usage of similarly acting drugs; usage of anticholinergics; usage of as required medications; usage of zuclopenthixol acetate: lithium and carbamazepine monitoring; usage of hypnotics and sedatives: monitoring the 
Table 2. Clinical condition and practice

\begin{tabular}{|c|c|c|c|}
\hline & $1992(n-32)$ & $1994\left(n=26^{\circ}\right)$ & $P$ \\
\hline $\begin{array}{l}\text { Subjects' condition } \\
\text { Mental state and behaviour } \\
\text { Stable } \\
\text { Unstable } \\
\text { Medication side-effects }\end{array}$ & $\begin{array}{l}20 \\
12 \\
12\end{array}$ & $\begin{array}{r}20 \\
6 \\
8\end{array}$ & \\
\hline $\begin{array}{l}\text { Clinical practice } \\
\text { Median depot dosage (CPZE) } \\
\text { All subjects (range) } \\
\text { Subjects without functional psychoses (range) } \\
\text { Median frequency (months) of psychiatric reviews (range) }\end{array}$ & $\begin{array}{l}255(25-2386) \\
308(51-2386) \\
2(0.03-24)\end{array}$ & $\begin{array}{r}119 \\
170 \\
3\end{array}$ & $\begin{array}{l}P<0.001^{*} \\
P=0.037^{\circ} \\
P=0.77^{*}\end{array}$ \\
\hline $\begin{array}{l}\text { Concomitant oral medication } \\
\text { Neuroleptics } \\
\text { Anticholinergics }\end{array}$ & $\begin{array}{l}20 \\
25\end{array}$ & $\begin{array}{l}16 \\
20\end{array}$ & \\
\hline
\end{tabular}

provision of user-friendly information to patients and carers on the risks and benefits of each medication; and ensuring regular assessment and documentation of both informal and detained patients' consent to treatment (Curran \& Hollins, 1994).

As more adults with $L D$ are resettled from mental handicap hospitals or remain living in the community, purchasers and providers are likely to expect high standards of psychiatric practice. Developing effective medication monitoring systems will become an essential part of clinical audit and quality assurance activities (Gravestock, 1994), particularly so in diverse dispersed multi-agency communitybased LD services.

\section{Acknowledgements}

I thank the consultants for their participation and Peter Willkinson for statistical support. Nick Bouras and Mike Timothy provided helpful comments on the manuscript.

\section{References}

AMAN, M. G. (1987) Overview of pharmacotherapy: current status and future directions. Journal of Mental Defclency Research, 31, 121-130.

BRTISH MEdical AsSOCIATION \& THE Pharmaceutical SOCIETY (1993) British National Formulary (BNF), No. 26. London: BMA \& Pharmaceutical Society.

CLARKE, D. J., KELEY, S., THINN, K., et al (1990) Psychotropic drugs and mental retardation: 1 . Disabilities and the prescription of drugs for behaviour and epilepsy in three residential settings. Journal of Mental Deficiency Research, 34, 385-395.

Craft, M. J. \& SCHIFF, A. A. (1980) Psychlatric disturbance in mentally handicapped patients. British Journal of Psychiatry, 137, 250-255.

Crammer, J. \& Eccleston, D. (1989) A survey of the use of depot neuroleptics in a whole region. Psychiatric Bulletin, 13, 517-520.
CurRan, J. \& Holuns, S. (1994) Consent to medical treatment and people with learning disability. Psychiatric Bulletin, 18, 691-693.

FRASER, W. \& NOLAN, M. (1994) Psychiatric disorder in mental retardation. In Mental Health in Mental Retardation led. N. Bouras), pp. 79-92. Cambridge: Cambridge Untversity Press.

GRAVESTOCK, S. (1994) Quality assurance for adults with mental retardation and mental health needs. In Mental Health in Mental Retardation (ed. N. Bouras). pp. 319 327. Cambridge: Cambridge Untversity Press.

- (1996) Depot neuroleptic usage in adults with learning disabilities. Journal of Intellectual Disabulity Research. 40. 17-23.

HARVEY, R. J. \& COORAY, S. E. (1993) Neuroleptic usage in a community mental handicap unit. Psychiatric Bulletin. 17. 657-660.

Kohen, D., Mathew, G. \& Fernando, L. (1993) Survey of psychotropic medication: usage in a large mental handicap hospital. Psychiatric Bulletin, 17, 137-139.

MANCHESTER, D. (1993) Neuroleptics, learning disability and the community: some history and mystery. British Medical Journal, 307, 184-187.

SAS INSTITUTE (1989) SAS/STAT User's Guide, Version 6 (4th edn. Vol. 1). Cary NC. USA: SAS Insttute.

ThinN, K. Clarke, D. J. \& Corbett, J. A. (1990) Psychotropic drugs and mental retardation: 2. A comparison of psychoactive drug use before and after discharge from hospital to community. Journal of Mental Deficiency Research, 34, 397-407.

WRESSEL, S. E., TYRER, S. P. \& BERNEY, T. P. (1990) Reduction in antipsychotic drug dosage in mentally handicapped patients: a hospital study. British Joumal of Psychiatry. 187, 101-106.

Shaun Gravestock, formerly Locum Consultant, Division of Psychiatry UMDS Guy's Hospital London; currently "Consultant in Psychiatry of Learning Disabilities, Northgate Hospital Morpeth Northumberland NE61 3BP

*Correspondence 